\title{
Teaching Timber: The Role of Studio Courses and Architectural Students Within an Interdisciplinary Research Project
}

\author{
CATHERINE SUNTER
}

The Oslo School of Architecture and Design

In 2013, the Wood Be Better (WBB) interdisciplinary research project was established, with the principal goal to produce and publicise knowledge that would facilitate the increased use of wood in buildings in urban areas in Norway. This article investigates six master-level studios at the Oslo School of Architecture and Design (AHO), from autumn 2013 to spring 2016, set up as laboratories for systematic architectural exploration within this research project. A set of structured, qualitative interviews with teachers, researchers and students, presents a broad account of the courses. The findings reveal an educational focus on investigating architectural solutions to complex urban situations and the development of technical and detailed knowledge in materials using the latest and expert knowledge within the interdisciplinary research team. The studios contributed to the research by illustrating the architectural implications of a variety of design alternatives, and in addition, embedded knowledge and interest in timber to the next generation of architects.

\section{INTRODUCTION}

As buildings become more energy efficient and emissions related to their operational use are reduced, the importance of embodied energy in materials becomes more significant. This explains a renewed interest in the use of wood-based materials in buildings from sustainably managed forests, substituting steel and concrete alternatives, as an effective means to reduce fossile energy use and mitigate climate change ${ }^{1}$. In addition to this, is the potential economic value in countries with an existing forest industry not used to capacity. In the wake of great city fires timber was gradually abandoned in urban buildings. New timber solutions and advanced technologies for fire safety have facilitated a reinvention of timber as an urban building material. Alongside this growing awareness of the sustainable merit and urban potential of wood is the need to research and advance knowledge in its use as a construction material.
The Norwegian Research Council's BIONAER program for the biobased sectors (primarily forestry, agriculture and aquaculture) funds the Wood Be Better (WBB) research project, which runs from January 2013 to December 2016. The principle goal of the project was to "produce and publicise knowledge that will facilitate increased use of wood in buildings in urban areas"2. WBB is a large interdisciplinary project with the Oslo School of Architecture and Design ( $\mathrm{AHO}$ ) as the leading and coordinating partner, instilling a clear and defined architectural and urban perspective into the project. AHO is partnered with the Norwegian University of Life Sciences (NMBU) and the Norwegian Institute of Bio-economy Research (NIBIO). A number of international research partners and Norwegian architectural firms and forest owners are also associated with the project. Five subtasks or work packages were defined in the WBB project description. Work package 2, the focus of this article, was titled "Design-based research"2 and proposed using master courses at AHO as "laboratories for systematic architectural exploration."2

This article examines the six consecutive masters studios in Urban Timber held at AHO between Autumn 2013 and Spring 2016, seeking answers to the following questions: what were the course intentions; how were they structured and themed; how did the research project influence the courses; how did the courses contribute to research. By interviewing key actors representing the teachers, researchers and students, the article aims to present an in-depth picture of what happened. In this way it is hoped to give an insight into this approach to teaching timber in an architecture studio, the integration of research and studio courses and the value of such courses to an architectural school.

\section{PEDAGOGICAL CONTEXT}

The reinvention of timber as an urban building material has resulted in the introduction of timber oriented teaching and research programmes at architectural schools across the globe. The following text introduces four current teaching programmes from Switzerland, Germany and Finland, giving a pedagogical context to the Urban Timber programme at $\mathrm{AHO}$.

The Laboratory for Timber Constructions (IBOIS) in the École polytechnique fédérale de Lausanne (EPFL) has been running since 2004. The 


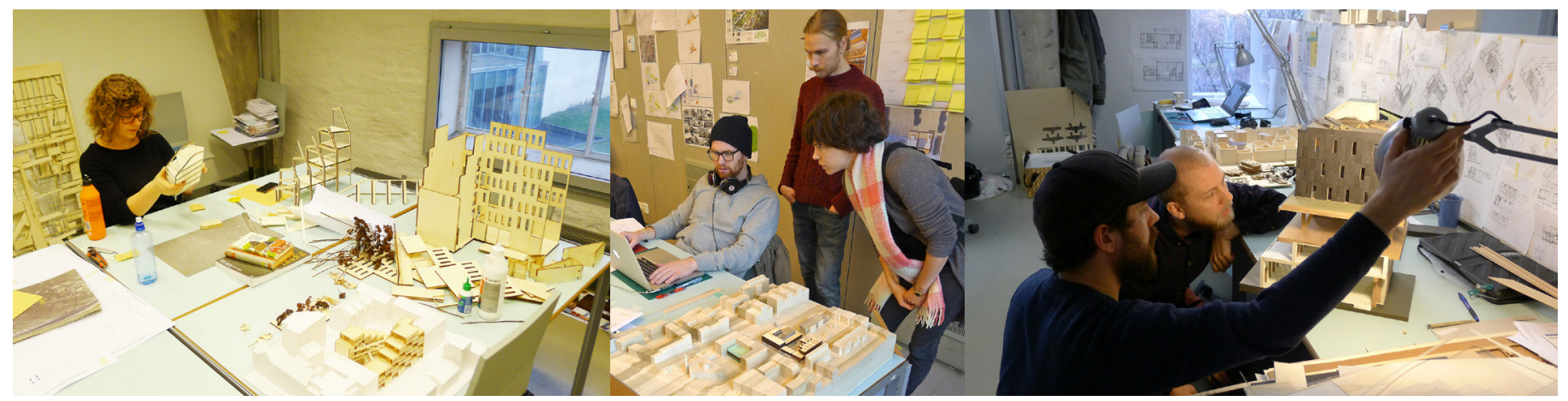

Figure 1. Studio as laboratory: Photographs of students from the autumn 2014 course in "Adaptable Urban Timber Building".

programme is led by engineer and architect Yves Weinand, and displays a strong connection between the architecture and technical and technological issues. The studio is described as having an "objective to develop constructive skills and reasoning that actively participates in the elaboration of the architectural project and which fosters its qualities." 3 The Wood in Research And Teaching programme at the Technical University of Munich (TUM), headed by timber enthusiast Hermann Kaufmann, has the ambition to "strengthen the use of timber as a construction material, and to intensify its contribution to a responsible use of available resources." 4 There is a strong focus towards interdisciplinary teaching with experts from science, architecture, forestry, the wood industry and construction practice. These courses share an ambition to use general architectural projects as the basis to explore the technical and constructional properties of timber.

In contrast, the following two programs investigate timber in a more concentrated method, resulting in 1:1 built prototypes. The Gramazio and Kohler Research Group at the Swiss Federal Institute of Technology in Zurich (ETHZ). The group's focus is primarily researching methods of fabrication and robotics in structures, examining "the changes in architectural production that result from introducing digital manufacturing techniques." 5 Although not focused primarily on the teaching of timber, they are interesting to review as their built prototypes have a tendency to use wood as the main construction material. The Wood Programme at Aalto University in Helsinki is a year-long design-and-build programme with a focus towards the structural principles of complex geometries in wood, ending up with an "experimental wooden building." 6

The Urban Timber programme at AHO was introduced in autumn 2013, as a key part of The Wood Be Better research project, an interdisciplinary project with the primary focus of increasing the use of wood in urban areas in Norway. Five work packages were set out in the original project plan, with work package 2 titled Design-based research. This introduced the use of masters level studio courses at the Architecture School in Oslo as laboratories exploring the effects of wood application on the functional, technical and architectural quality of whole buildings and areas. The ambition was to utilise the core competence of architects, whilst producing a depth and breadth of results not possible in ordinary research because it is too expensive or too slow.

\section{THE INTERVIEWS}

The interviews that form the basis for this article were undertaken in March 2016. The interview subjects were chosen for their particular involvement in the project and to give a variety of voices to the research. As the total number of teachers and researchers numbered only five it was possible to interview all. The five student interviewees were selected from a total of 75 based on the contribution of their projects to the research project. All the participants were familiar to the author, who had joined the WBB research project in August 2015 as project coordinator and teaching assistant. It was anticipated that this familiarity would encourage honest and open participation. A set of 15-20 questions, adapted to each interviewee, was prepared by the author and used as a guide during the interviews. They were not sent out prior to the interviews to encourage a more intuitive and explorative dialogue. The author observes that these students represented only three of the six urban timber courses. At the time of interviewing they had recently graduated from AHO (January 2016) enabling a reflection and openness perhaps not available from continuing students. The author notes that all the student interviewees chose to continue with the project and course leaders after concluding their studios, either through their choice of diploma supervisor or working environment, indicating an inherent bias in their answers.

\section{COURSE INTENTIONS}

The introduction of a set of master courses as laboratories within the research project built on the unique position of the architecture environment at the centre of the interdisciplinary research group. The ambition was to realistically test the research and assess its impact on practical work by illustrating the industrial and architectural potential of the new constructions and new methods in timber in the designs for whole projects. Through the master studios, the students could produce many and varied project examples, showing detailed timber solutions integrated into complete, complex and holistic architectural designs, something not possible in traditional research projects where the researchers are too expensive and too few. Børre Skodvin, course leader of the spring semesters, remembered, "it was thought that if we could give the students this kind of access to the research front, the latest knowledge... and just see what happens, that would be a kind of design test". At the same time it enabled the students to take part in research-oriented studios that produced full individual projects, in contrast to the small and limited tasks often produced as a sub-delivery of a larger research project. 


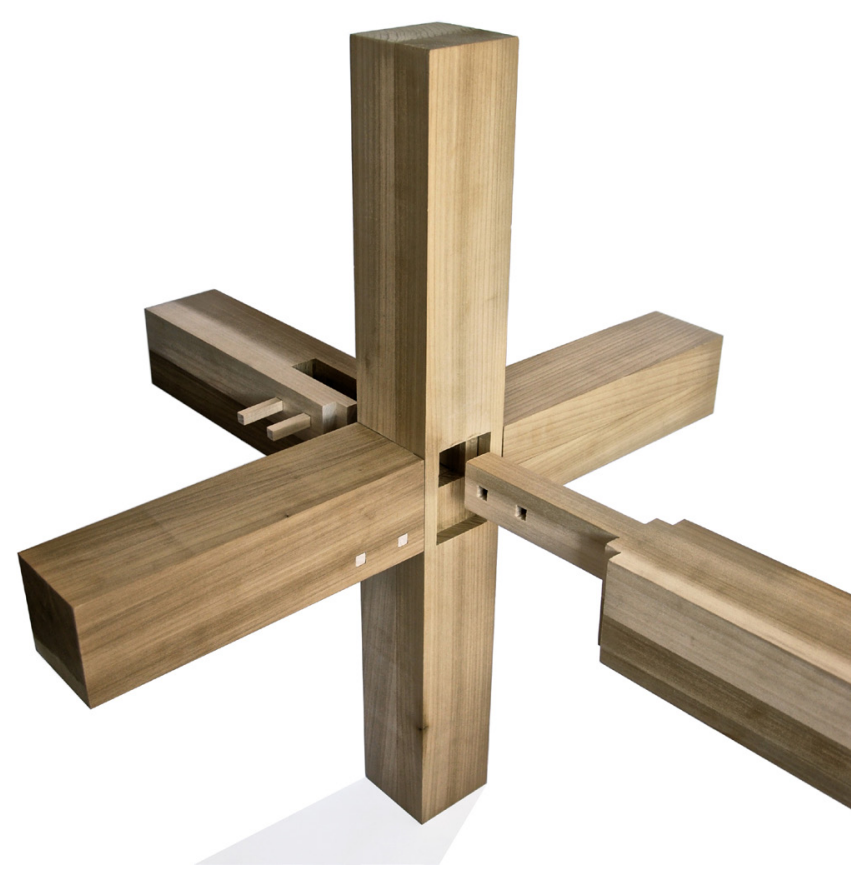

Figure 2. Exploring wood to wood connections: Wooden Joinery House, Kamilla Kristiansen. Spring 2015 "Forest-Wood-Building”.

\section{TWO STUDIOS}

The timber courses were organised as two masters studios, one in the autumn semester and one in spring, with the first in autumn 2013. The autumn courses, led by Marius Nygaard, explored timber construction in large, complex and typical urban projects, such as the urban block and urban infill. There was a particular focus on the use of Cross-Laminated Timber (CLT) as a material that had been proven to be well-suited to urban densification projects, as well as constructions that explored the potential for buildings to change according to different use over time. Teaching assistants Lars and Ute noted that these courses had a "strong technical" and more "structured side". Ona and Eskil, who had taken both courses, commented that this course "took more of the engineering point of view, the economics of it, ... flexibility, and the wood industry" and was focused towards the "broader, larger scale of urban development and bigger projects generally".

The spring courses looked at different aspects of timber technology and the timber industry, to develop and explore different constructions and the potential to "misuse a material". Marius observes that they were "oriented towards the specialised use of wood, finding the timber resources that have special properties and then integrating them in the architecture in a deliberate way." Lars commented that they were "more experimental in the approach, where the development of ideas, ... building techniques and ... different uses of wood are emphasised". These courses had an experiential nature, getting to know the quality and character of wood and what it is like to work with. Børre recalls taking the students on a "winter experience, going into the snow and learning the chainsaw from this old timber guy on cutting down the tree".
The teaching staff agree that both courses had a different perspective on teaching timber, reflecting their course leaders personal interests and affinities, yet were complimentary to one another and the goals of the research project. Lars reflects that the ambition for both courses was "for each student to create a consistent and believable project that can be built ... which includes drawings and details that are well thought out and buildable" summarising that "the difference lies in approach, rather than a goal". The students noticed these differences, Ona reporting, "I experienced them as two very different courses and with a very different focus, and ... intention ... of where they wanted us to go and what they wanted us to learn". Eskil notes "I chose these courses because of the contrast of those approaches ... the chronology was kind of right to me. To first learn about the properties and then trying to implement it in some way that I felt was interesting or trying something new."

\section{CHOICE OF COURSE}

Marius remembers being forewarned not to expect many students in a research-oriented studio, but it turned out that they had many more applicants than the 15 they could accommodate. He suggests this "combination of research orientation in the form of a traditional and very ambitious studio course, it was looked upon ... as a very attractive solution for a course."

The students had many different reasons for choosing the courses, one of which was the course leaders' personalities and fields of interest. Ona stated directly "in truth I chose it because of the teachers. I just wanted to have Marius as my teacher", adding she would have taken Børre's course "regardless of what he was teaching", although it also seemed "incredibly interesting". Eskil agreed, "I think that is quite important when choosing a course ... who is going to teach you ... for a whole semester". In a subsequent interview with Marius he responded to this, saying "you can make the world's best course descriptions, but you will not get students unless you build a reputation for being a teacher who is present and able to communicate in ways that are understandable and inspiring."

Marte raises the sustainability aspect as one of her reasons, citing Marius as one of the main professors tackling sustainability. Interestingly wood plays a lesser role in the student's choice of course than learning principles of materials, detailing and construction. Even noted that he chose the course "to learn a little bit about detailing actually ... so it wasn't really about the wood thing". Eskil commented that he was interested in learning about the properties of wood and how that affected the detailing and the final look of the buildings, but "I'm not just interested in wood. I'm not a wood person. So I like to separate the wood and the course a bit. Because when it comes down to it, it's all about architecture to me."

Shohreh sums up these complex and varied reasons "I felt like the three first years [at AHO], they weren't so detailed. And not so focused on environment and how to use construction as a positive thing, so I wanted to really dig into details and understand construction and how to use wood as well. Because I think we have a great opportunity in 

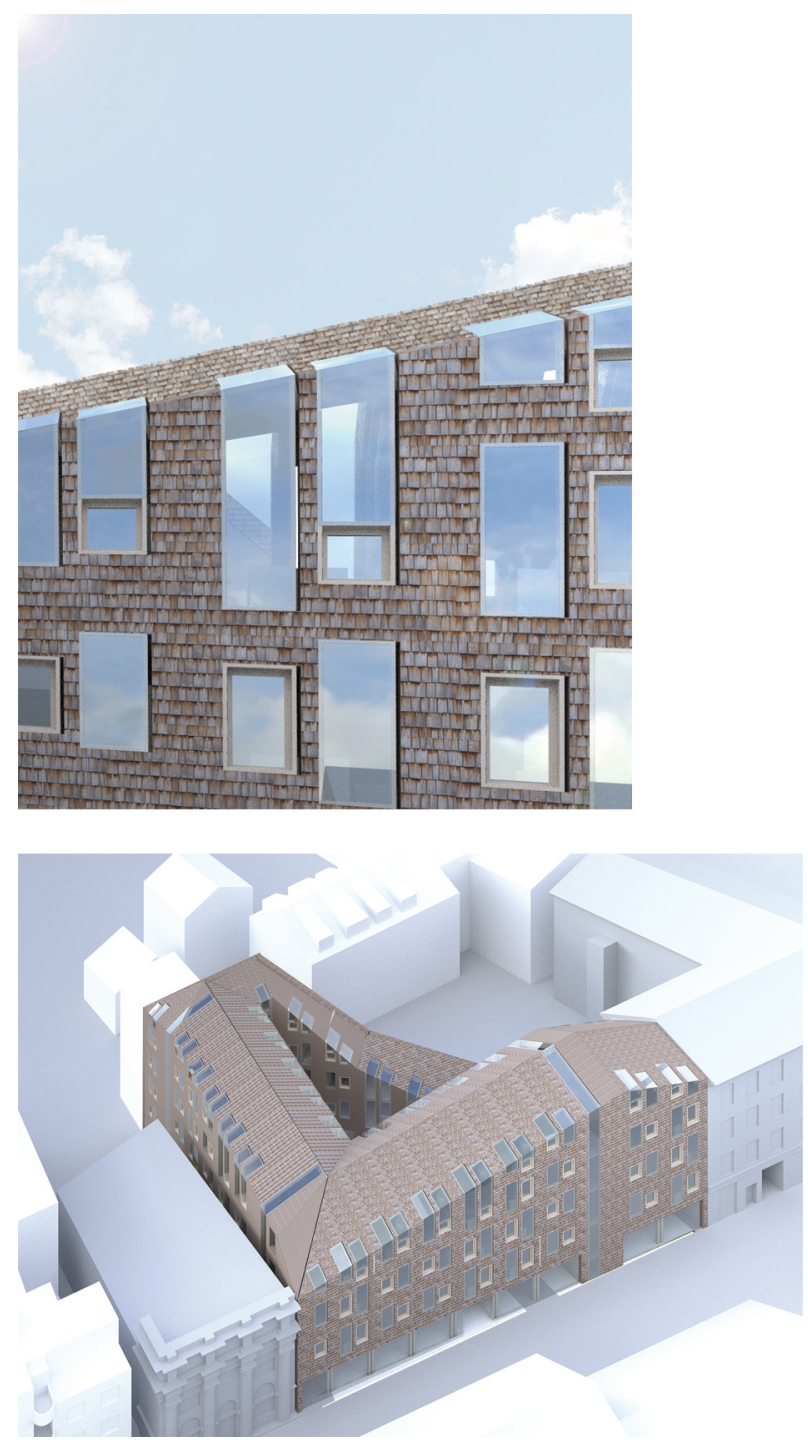

Figure 3. From concept to detail: Nordregate 20/22, Ingrid Engøy Henriksen and Katrine Hamre Sørlie. Autumn 2014 "Adaptable Urban Timber Building".

Norway to use wood. And it's lacking a lot because we don't know so much as we should, especially in big buildings."

\section{FROM CONCEPT TO DETAIL}

The shared ambition of the two courses was to carry ideas all the way from concept to detailed designs and make drawings that resemble working drawings. Marius notes "I think we quickly saw that there were coming rather good projects with a level of detail that was not usual at the school". Børre added that they "brought to light some interesting discussions", in particular dealing with architectural possibilities of the exterior shell. Ute noted this as one of the main advantages of these courses, but emphasised the need to consider both the concept and material together from the beginning to "create a much stronger solution". It was sometimes challenging to work from the concept to detail level in one semester. Marius comments "we have to lift the students' competence in wood technology very quickly, and we have to use a lot of time for that" adding that he would like to "meet the students on a more advanced level ... and

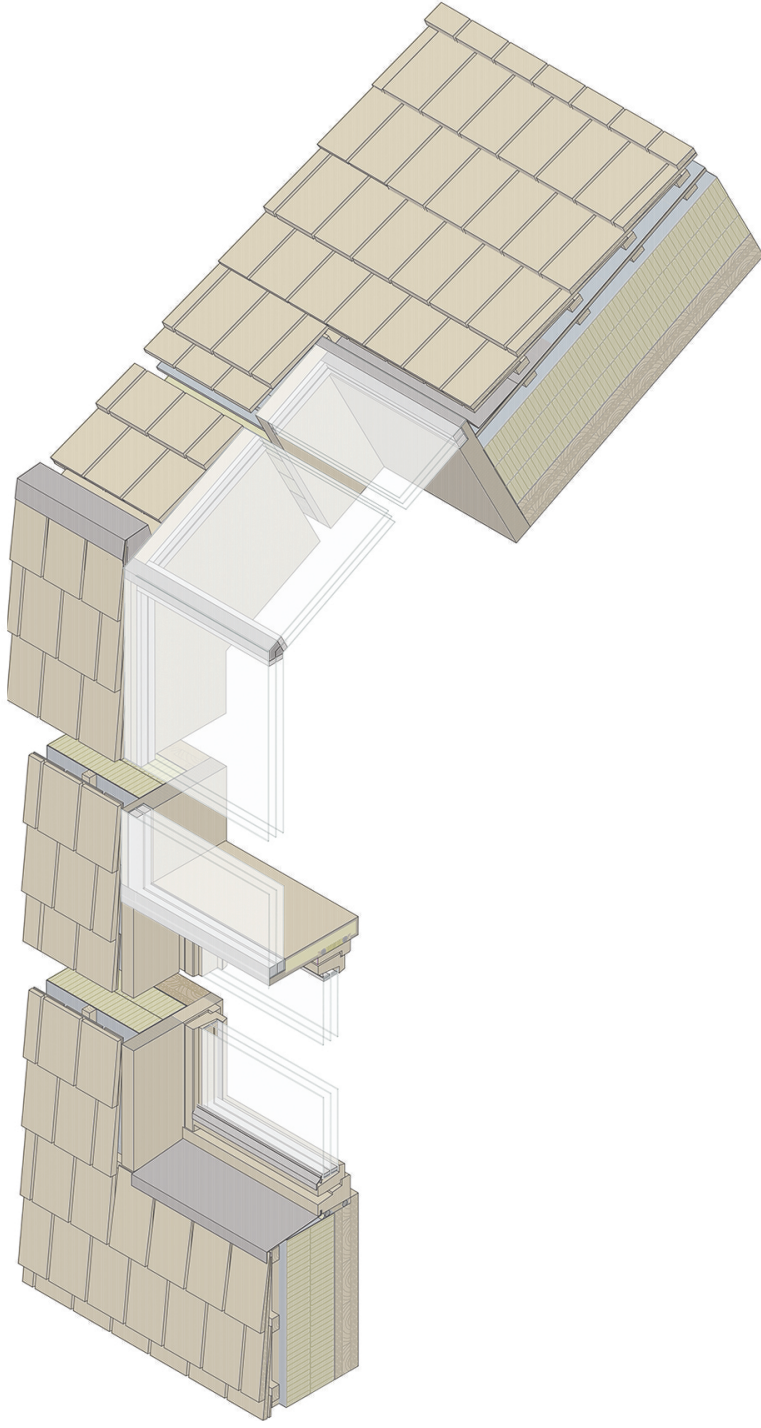

then work more balanced with the technical and architectural solutions." Ona experienced it took too long "finding the right architectural expression", which limited how much her research into timber could be integrated within her design. Conversely, Marte found the course "quite well-organised" and noted that "the detailing phase is where I thrive". Even adds "we started designing the details really early actually, and that was a really nice experience to develop them alongside the plans and sections while we were still figuring out how everything was going to look... I've never made a project that was that holistic where we thought about most of everything from the structure to the design to the city plan to the details. I'm really happy that we got as far as we did."

Shohreh notes "I remember when ... I studied [Sverre] Fehn's architecture, and I was kind of falling into this dreamy, poetic world, but then I realised the poetic part is actually in Fehn's details, ... and how the materials meet each other so precisely, and if he hadn't that detail knowledge, I don't think his poetry or his story would have come out as professionally as it has come out. So, I think that's why there should also be a focus on details at school, to really bring out the story and bring out the poetry in the architecture." 

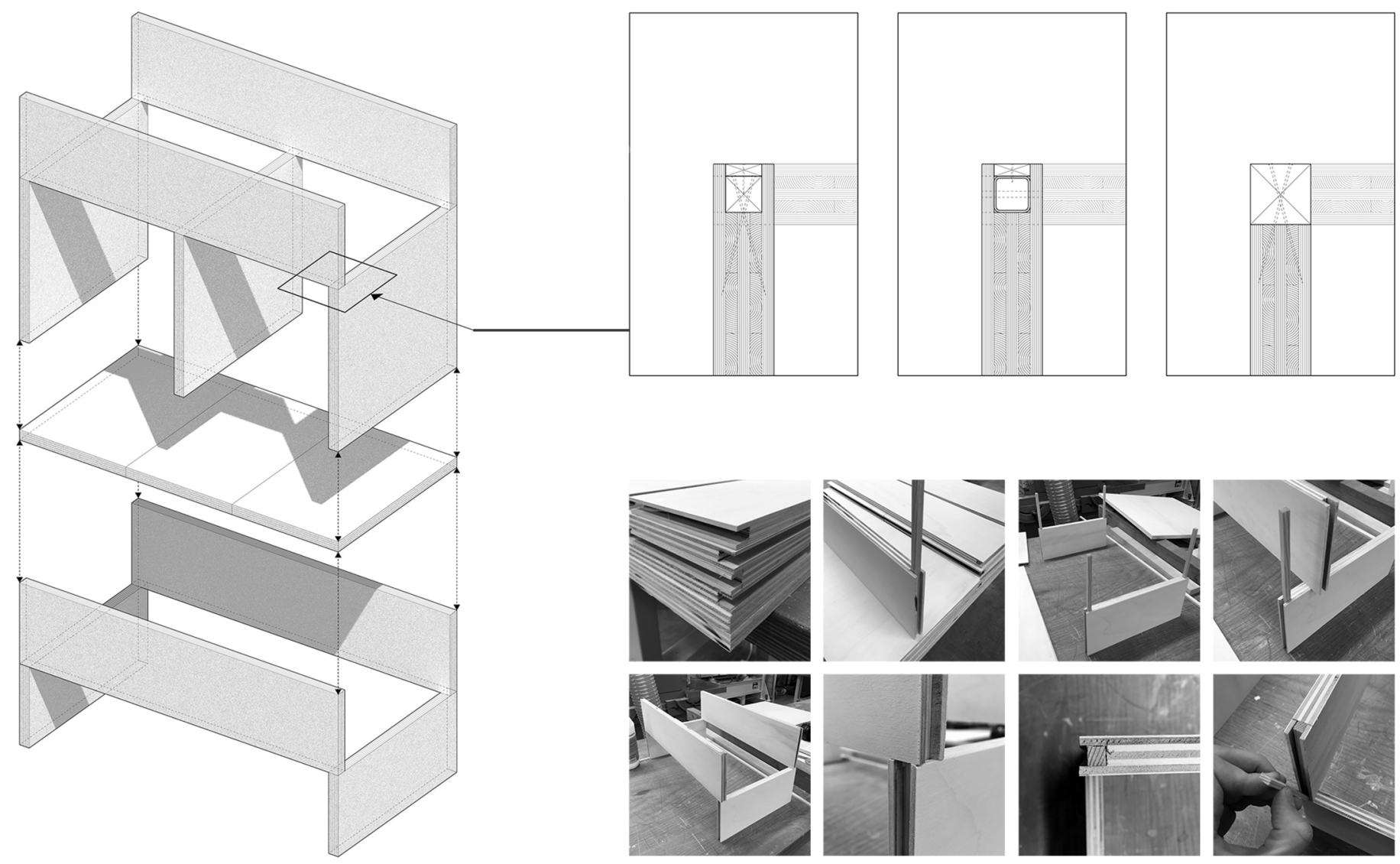

Figure 4. Exploring alternative constructions in CLT: 9 IN WOOD, Eskil Frøyen

Nybø. Spring 2015 "Forest-Wood-Building".
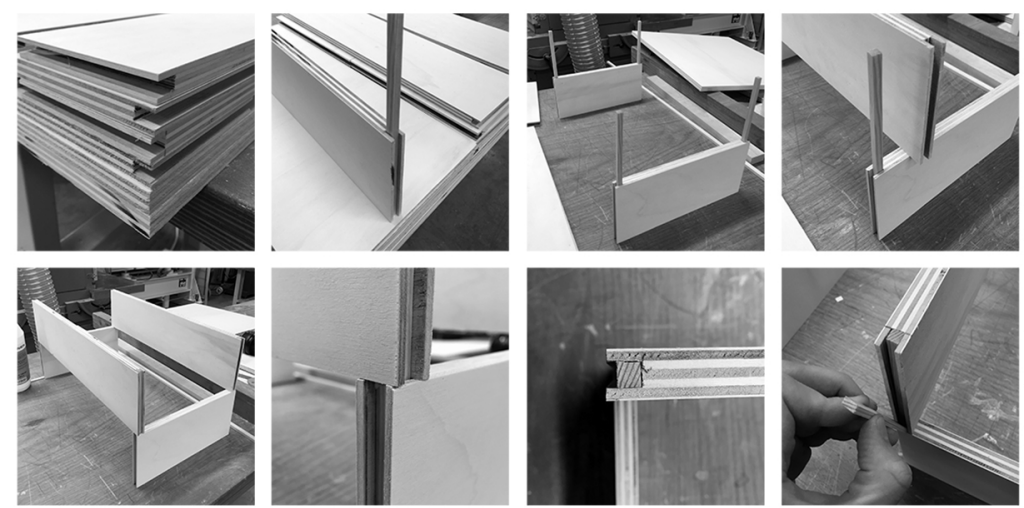

\section{WHEN IS TIMBER APPROPRIATE?}

In designing and planning the courses there was an aspiration to use the focus of investigating timber as a construction material, as a tool to teach architecture at the level of a masters studio, whilst also exploring the materials versatility in an urban context. As Børre emphasised, the main focus was in the pursuit of the best possible architectural project, despite being a timber course. Ute explained "it was quite important to say, it doesn't have to be timber in any case, but to see where it is good". Lars and $B \varnothing r r e$ highlighted that this was a potential problem with this type of course "you could imagine ... that you could have a type of material racism, where you have a preference for a particular material, which was unreflective and which didn't really consider if the material was appropriate". Eskil remembers "what I learned during this course was that the hard question is - when is timber appropriate?"

\section{INTERDISCIPLINARY EXPERIENCE}

One of the main benefits of the research-oriented course was the access to very highly skilled and knowledgeable people. The students were given up-to-date input early in the courses on the principal properties of timber, the production of forest, different constructions and the qualities of timber cladding. They had visits from highly profiled architects with experience in the field; as well as biologists, acoustic, fire and structural engineers from within the research consortium; and producers of timber products. Børre described this as similar to "having a laboratory with very nice tools and a very good technician". Jan describes the advantages and

challenges of "bringing [the students] up to date with the current state of technology" and "in touch with what's going on in the world" in a way that "doesn't overburden them with information." Eskil notes that he found it interesting to talk to "non-architect people" and "understand more of what is going on out there". Børre reflects on studio discussions around unsolved problems amid these experts, "I will expect that gives you a feeling as a student, that you know something that not everybody out there will be aware of. It will give you an edge, and ... shows you that no material, however well-known or well-studied, is ever finally completely exhausted as an object of study." Marius reports "when we have had people from the industry in the studio, they are very positive and they are very impressed by the level of knowledge achieved by the students", and reflects on the potential for architects to work more closely with industry in the future, developing building systems to enable them to be more adaptable for different types of applications.

The interdisciplinary element of the research played a part in one particular masters project, where a student of engineering at NMBU and a group of architectural students at AHO worked together to research and test the capacity of cross-laminated timber walls used as large cantilevered beams in a typical housing project.

\section{STUDY TRIPS}

Study trips were a key contribution to each of the courses, with visits to Finland, Japan, Ireland and the alpine regions of Austria, Germany and Switzerland. The study trips enabled the students to experience first-hand built examples of both traditional and contemporary architectural projects, from countries with a long-standing timber culture 

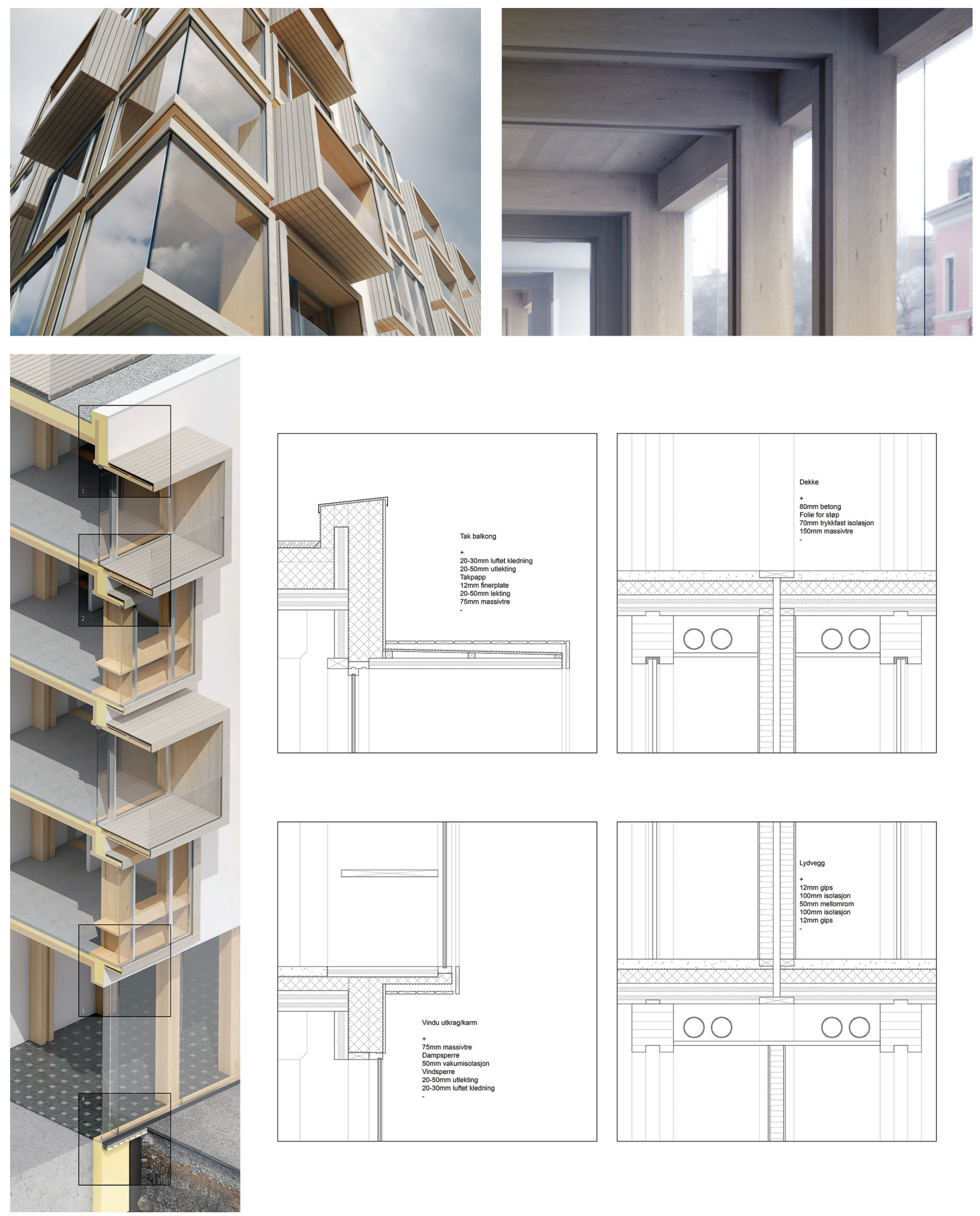

Figure 5. From concept to detail: A building kit in wood, Eskil Frøyen Nyb $\varnothing$ and Even Småkasin, autumn 2014 "Adaptable Urban Timber Building”. 
and an advanced knowledge of detailing and technical development. In addition the students could learn about the technical processes from visits to CNC factories and timber module production sites. Reflecting on the Japan trip Lars observed "just being able to see it and touch it makes you able to try to reverse engineer it and think of how you could achieve this at home, and it's definitely possible."

\section{CONTRIBUTION TO RESEARCH}

The main contribution of the studio courses to the WBB research are the many and varied student projects exploring timber as a main building material in different urban scenarios in Oslo. As Eskil noted the studios have created "a huge selection of works" and a valuable resource. The projects illustrate the link between designs on an urban level, building and detailed level, showing as Ute reported "the different aspects that we are interested in, but combined into a real product, because you can look at isolated aspects but they really only make sense when they are combined into a meaningful whole." Shohreh thought that the freedom to experiment within the project tasks added value to this contribution "because we were so free in doing what we wanted, but still have this very constructive line of How do we actually do it? Is it manageable, or is it just a drawing?"

\section{ADDITIONAL PERCEIVED VALUE}

All the interviewees were asked to reflect on the overall value of these master courses. The student responses emphasise contributions noted earlier in the article. Marte mentions "the possibility to contribute and influence" this new field and the "cooperation across disciplines, which really was helpful and inspiring for our professional career afterwards." Shohreh reflected on the value of these types of courses to the "students' variety of knowledge" and "because we are architects, and at the end, we are going to build our buildings." Jan comments that "organising a studio around real-world problems has the potential to give the students the feeling that their ideas, their exercises, their efforts are really capable of influencing the world."

Børre emphasised the embedding of knowledge and interest in timber as a building material to the students, which "in a small country like Norway ... is a very efficient seedbed" adding "it's kind of a future yield, a little bit like in the forest. You plant the seed and you wait for a generation, and maybe you get a nice tree." Marte and Even agreed that they would like to continue working with wood as a construction material, which Ona observed would "shift industry in the long run". Shohreh had already influenced an architect to consider the use of timber instead of brick on a façade. Eskil concluded "what better way to introduce wood into architecture than to teach the new students? Because we are the generation that is going to be architects in the future. So instead of convincing the established architects out there, you kind of go in early. Like, teaching kids how to walk."

Marius reflects on the value to the architectural school, "I think it has had a rather dramatic effect ... because it actually has created a new permanent area for teaching... And it creates a platform for further cooperation with industry because they see that we ... have made projects to a level of detail ... which approaches the level that they need to develop new products." Børre was similarly excited about the implications on the teaching and research environment at $\mathrm{AHO}$, and the potential to become experts in a field "for which we have a talent" adding "it would be precisely this kind of place, you know, - Who are you going to call? - Well, we'll call the timber department at AHO, because if they don't know, then nobody knows."

\section{DISCUSSION}

During a follow up interview with project leader Marius Nygaard, he reflected on the results of these interviews in light of the original course intentions. He particularly noted his surprise at the weight that the students put on the teachers in the choice of course, adding that "as a teacher, it's important to have that in mind."

He also reflected on the need to keep up the ambitions on behalf of the students of embracing complexity instead of artificial simplicity. He highlighted the importance of giving the students both a feeling of mastery of the intricacies and the complexity of real-world projects, whilst at the same time enabling a level of control and an overview from which they can steer the process in a direction of their own architectural identity. He concluded by saying "I think it's very important to maintain an open attitude when it comes to what can be the sources and inspirations of architectural design, but at the same time build a competence in discussing, arguing and showing how these inspirations can be developed into sensible and sustainable architectural solutions."

\section{ENDNOTES}

1. IPCC (Intergovernmental Panel on Climate Change), Climate Change 2007: Synthesis Report. Contribution of Working Groups I, II and III to the Fourth Assessment Report of the IPCC, Geneva, Switzerland, IPCC, 2007.

2. Increased use of wood in urban areas - WOOD/BE/BETTER: Oslo School of Architecture and Design response to the Call for Proposals. 2012

3. Design Studio Weinand, Laboratory for Timber Constructions, IBOIS. http://ibois. epfl.ch/page-10904-en.html

4. TUM.wood - Wood in Research and Teaching, Technical University of Munich. http:// www.wood.tum.de/index.php?id=5\&L=1

5. Gramazio Kohler Research, ETH Zurich. http://gramaziokohler.arch.ethz.ch/web/e/ about/index.html

6. Wood Program in Architecture and Design, Aalto University School of Arts, Design and Architecture. http://woodprogram.fi/introduction/ 